\title{
Histopathological Changes of the Flaxseed Extract on Skin Wound Healing in Diabetic Rabbits
}

\author{
B. E. Mustafa Al-Ahmad ${ }^{1}$, M. A. Kashmoola ${ }^{2}$, Omar Abdul Jabbar $^{2 *}$, K. I. Mokhtar ${ }^{1}$, N. Mohamad ${ }^{3}$, R. Abdul Rahim ${ }^{4}$, \\ Mustafa Nazih Shaban ${ }^{2}$ \\ ${ }^{1}$ Department of Fundamental Dental and Medical Sciences, Kulliyyah of Dentistry, International Islamic University Malaysia, \\ Kuantan, Pahang, Malaysia; ${ }^{2}$ Department of Oral Maxillofacial Surgery and Oral Diagnosis, Kulliyyah of Dentistry, International \\ Islamic University Malaysia, Kuantan, Pahang, Malaysia; ${ }^{3}$ Department of Pathology and Laboratory Medicine, Kulliyyah of \\ Medicine, International Islamic University Malaysia, Kuantan, Pahang, Malaysia; ${ }^{4}$ Department of Basic Medical Science, \\ Kulliyyah of Medicine, International Islamic University Malaysia, Kuantan, Pahang, Malaysia
}

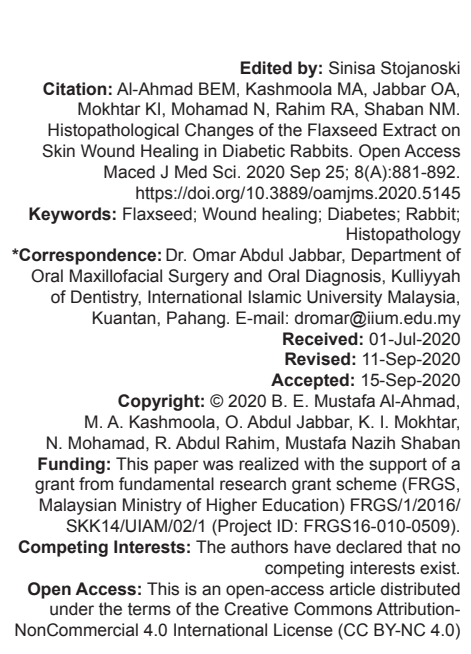

\section{Introduction}

The diabetes mellitus is one of the chronic diseases that affect more people worldwide [1]. This disease leads to severe complications such as chronic wounds and diabetic foot ulcer [2]. The prevalence of chronic non-healing wounds is around $15 \%$ of all diabetic population, with up to $66 \%$ of the subjects admitted to the hospital with diabetic foot osteomyelitis [4].

Infection with increased inflammatory markers is closely related to the pathogenesis and complications of diabetes, which, in turn, may increase the incidence of diabetic foot ulcer. In addition, the balance between pro-and antiinflammatory processes is vital in the development of wound healing. Diabetic peripheral neuropathy, peripheral vascular diseases, impaired angiogenesis, and chronic inflammation are multifactor that initiates the impaired wound healing [5].

Wound healing is a complex process that involves simultaneous action of soluble mediators, blood cells, extracellular matrix as well as mesenchymal cells. The process is composed of four overlapping phases, homeostasis/coagulation, inflammation, proliferation (granulation tissue formation), re-epithelialization, and remodeling [6]. Molecular and cellular processes during the inflammatory stages of skin healing are initiated and amplified to a large degree by a group of protein mediator known as pro-inflammatory cytokines [7]. Pro-inflammatory cytokines synthesis and activity are affected by the concentration of omega- 3 fatty acids. In a study by McDaniel, it was observed that omega-3 fatty acids supplementation in a healthy human population for 4 weeks resulted in increased production of proinflammatory cytokines, including interleukin-1 $\beta$ (IL$1 \beta$ ) at wound sites and thus, depending on the clinical 
content, has non-invasive, therapeutic potential to affect cutaneous wound healing. In addition, omega- 3 fatty acids supplementation in microenvironment of acute human wounds improved wound healing [8]. Almost all earlier studies have evaluated the effects of omega-3 fatty acids from fish oil supplements on wound healing among patients with diabetic foot ulcer.

Flaxseed oil (FO), a plant-derived omega-3 ( $\omega-3)$ polyunsaturated fatty acids (PUFAs), is rich in $\alpha$-linolenic acid (ALA) (40-60\%) which has been proved to benefit for chronic metabolic disease. However, the exact effects of dietary flaxseed oil on T2DM remain largely unclear [11]. Furthermore, data on the effects of omega-3 fatty acids on wound healing are conflicting. Regarding the effect of omega-3 fatty acids on inflammatory phase of healing process, a meta-analysis study has demonstrated that marinederived omega-3 supplementation had a significant lowering effect on C-reactive protein (CRP), IL-6, and tumor necrosis factors $\alpha$ (TNF- $\alpha$ ) level [9]. It has been previously shown that taking omega- 3 fatty acids from flaxseed oil (1 $\mathrm{g} /$ day) for 12 weeks among diabetic neuropathy (DN) patients had favorable effects on markers of insulin metabolism, serum triglycerides, and VLDL-cholesterol, but did not affect biomarkers of inflammation and oxidative stress [1]. However, no significant change in insulin levels was seen following supplementation with $3.6 \mathrm{~g}$ of omega-3 fatty acid among patient with chronic kidney disease for 10 weeks [10].

Although many synthetic medication and/ or chemical products are used for wound healing, complications, side effects of these agents are not deniable [12]. Studies have drawn attention to protective effects of medicinal plants on wound healing [13], herbal medications have special characteristics which distinguish them from chemical drugs such as prolonged safe usage, lower costs, and less side effects [14]. Several plants have been accustomed to investigating their therapeutic properties on wound healing; however, therapeutic efficacy of those plants is still controversial. Flaxseed (Linum Usitatissimum) is known as a rich source of the essential fatty acids, unsaturated fatty acids, and phenolic compounds, it is reported that high antioxidant potential of flaxseed enhances immune system, as well as antimicrobial, antioxidant, and antiinflammatory properties [15]. The pharmacological properties of linseed oil are attributed to the presence of poly unsaturated fatty acids (PUFA) and mono unsaturated fatty acids (MUFA) in its composition that acts stimulating production of growth factors, fibroplasia, and neovascularization [16]. Previously authors reported that linoleic acid ( $\omega-6)$ exhibits proinflammatory characteristics, whereas linolenic acid ( $\omega-3)$ and oleic acid ( $\omega-9)$ have an anti-inflammatory effect [17]. During a study evaluating the impact of topical administration of purified linolenic, linoleic and oleic acid, on the process of wound healing in rats, [18] determined that a favorable impact of MUFA oleic and PUFA linoleic acids on the process of tissue repair, specifically as proinflammatory agents throughout the inflammatory phase of the healing process [18]. It is noteworthy that linoleic acid $(\omega-6)$ is the direct precursor of arachidonic acid, which prevents transepidermal water loss, provides elasticity, skin integrity and fluidity [19], and serves as a substrate for the synthesis of eicosanoids such as prostaglandins, leukotrienes, and thromboxane, these, in turn, modulate immunological and inflammatory responses by altering leukocyte functions and accelerating the process of tissue granulation [21].

The beneficial effects of flaxseed on wound healing may be related to its anti-inflammatory and antioxidant action [22]. Moreover, modulating the secretion of adipocytokines and inflammatory markers and enhancing fatty acids $\beta$-oxidation by omega- 3 fatty acids may improve methanolic profiles in patients with diabetic foot ulcer. As there is evidence that taking omega-3 fatty acid may accelerate wound healing and has anti-diabetic effect [23], we hypothesized that flaxseed oil topical application might help subjects with diabetic skin ulcer to heal their wound faster and have better biomarkers of inflammation and oxidative stress [24].

\section{Materials and Methods}

\section{Animals and housing}

The Animal Ethics Committee of international Islamic university Malaysia (CREAM) approved our study protocol [IIUM/ IACUC Approval/2016/(11)(76)]. The guidelines for using laboratory animals were strictly followed throughout the study [25]. Forty-five healthy male local bred white New Zealand rabbits weighting $1800 \pm 200 \mathrm{~g}$ of $6-8$ months in age were used in this study. Animals were housed in a $12 \mathrm{~h}$ light/dark environment with a temperature of $23^{\circ} \mathrm{C}$. Pellet which contains proteins and vitamins with tap water was provided ad libitum.

\section{Induction diabetes streptozotocin}

The dose used to induce diabetes in rabbit using STZ varies from 40 to $60 \mathrm{mg} / \mathrm{kg}$ [26]. STZ could be injected intravenously or intraperitoneally, rabbits injected intraperitoneally with STZ $(60 \mathrm{mg} / \mathrm{kg}$ ) have shown a significant increase of fasting blood glucose level $(299 \pm 10 \mathrm{mg} / \mathrm{dl})$ comparing to control rats $(49 \pm$ $6 \mathrm{mg} / \mathrm{dl}$ ) [27]. STZ was reported to be highly effective when injected intraperitoneally in white New Zealand rabbit, these rabbits exhibit high blood glucose levels following a single STZ injection without the need for repeated administration [28], [29]. 


\section{Preparation of the animals}

Xylazine (Sanofi, France) in a dose of $1.25 \mathrm{ml}$ was given as an intramuscular injection to induce sedative hypnotic condition; this is followed about $10 \mathrm{~min}$ later by an intramuscular injection of $8.75 \mathrm{ml}$ of Ketamine hydrochloride (Claris, India) to obtain dissociative anesthesia. After achieving anesthesia, rabbit eye was hydrated with normal saline to prevent corneal defect due to anesthesia induced eye dehydration. The operative fields were properly draped by sterilized towels and disinfected by Betadine solution (Povidone-iodine 10\%).

\section{Surgical procedure and study design}

In this study, four full thickness linear wounds were made on the skin both sides of interscapular region on each rabbit back. Incisions were $15 \pm 5 \mathrm{~mm}$ in length determined by surgical marker and measured using digital caliber, $4 \mathrm{~mm}$ wound depth was to the full thickness of the skin. A surgical blade No.15 (Romed, Holland) was used to make skin wounds with separation distance between the incisions not $<3 \mathrm{~cm}$ as recommended by Jawad 2013 [30] as shown in Figure 1.

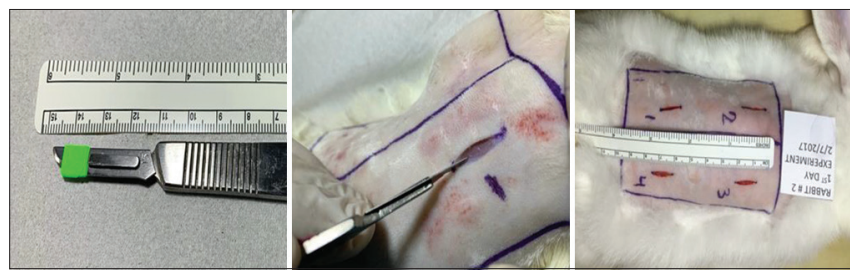

Figure 1: Surgical technique used to create superficial linear wounds on rabbit backbone skin area

After performing incisional wounds, 45 male white New Zealand rabbits were divided into two main groups diabetic and non-diabetic each group is divided into three groups $(n=9)$. Diabetic animal group include: (1) Study group (adding Flaxseed), (2) positive control group (adding fucidin cream $2 \%$ ), (3) negative control group (no treatment). The same distribution of nondiabetic animals groups was followed accordingly, as shown in Figure 2. Four linear-shape, full-thickness wounds were made in both sides of the backbone skin in each animal. Tissue samples were obtained at days $4^{\text {th }}$, $7^{\text {th }}$, and $14^{\text {th }}$ post wounding for microscopical analysis, histopathological parameters included inflammation, re-epithelialization, neovascularization, and surface closure rates as shown in Table 1.

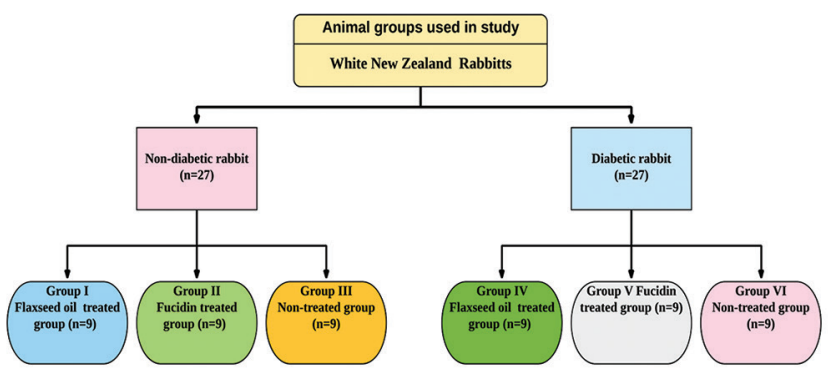

Figure 2: Experimental groups of white New Zealand rabbits for wound healing study

\section{Histopathological examination}

Semi-quantitative method was used to evaluate following histological processes and structures: Reepithelization, PMNL (polymorphonuclear leukocytes), fibroblasts, new vessels, and new collagen. Sections were evaluated according to the scale: $0,1,2$, 3 , and 4 by two independent observers, parameters for histologic assessment of wound healing according to Gal et al., 2008, during wound healing of rabbits. $\mathrm{H}$ and E stain [31] as shown in Table 1. The mean value was used for statistical comparison.

\section{Results}

Flaxseed extracts reported positive results in histopathological assay tested on wounded skin of the rabbit. This is crucial to determine cellular changes in each treatment and the results would be able to justify whether extract did the most effective treatment in wound healing. This study examined the chronological histology of wound healing to define wound architecture and showed the following:

\section{Four days after incisions preparation}

The histological findings show a moderate to heavy inflammatory cell infiltration from the base to the surface. The incision site was clean without any remnant necrotic tissue. The reepithelization, inflammatory cell infiltration, and surface closure rate parameters of flaxseed, fucidin, and non-treated groups both diabetic and non-diabetic animals showed different histological scores at different intervals, presented at ( $\times 40$ and scale bar $100 \mu \mathrm{m})$, as shown in Figures 3-6.

Table 1: Explanation of scale used in the semi-quantitative evaluation of histological sections

\begin{tabular}{|c|c|c|c|c|c|}
\hline Scale & Epithelization & PMNL & Fibroblasts & New vessels & Collagen \\
\hline 0 & Thickness of cut edges & Absent & Absent & Absent & Absent \\
\hline 1 & Migration of cells $(<50 \%)$ & Mild ST & Mild-ST & Mild-SCT & Minimal-GT \\
\hline 2 & Migration of cells $(\geq 50 \%$ ) & Mild DL/GT & Moderate-GT & Moderate-GT & Moderate-GT \\
\hline 3 & Bridging the excision & Moderate DL/GT & Moderate-GT & Moderate-GT & Moderate-GT \\
\hline 4 & Keratinization & Marked DL/GT & Marked-GT & Marked-GT & Marked-GT \\
\hline
\end{tabular}


a. Reepithelization parameter at day 4 shown that the mean reepithelization of control group was the highest among NDM group while flaxseed showed higher mean than fucidin and the control group in the DM group. Nonetheless, the difference was not sizable to achieve statistical significance, $(p=0.273)$ and $(p=0.080)$, respectively, as shown in Table 2.

b. Inflammatory cell infiltration parameter at day 4 of the NDM rabbit group did not show statistical significant with the presence of a minimal mean difference $(p=0.637)$, that is, the mean of inflammatory cells of NDM rabbits was highest among fucidin, flaxseed then, and lowest for control group. In regard to DM rabbits, the difference reached border line statistical significance $(p=0.119)$ where the inflammatory cells mean was highest among fucidin group then flaxseed and lowest for control by the $4^{\text {th }}$ day (Table 2 ).

c. Surface closure parameter at day 4 shows that

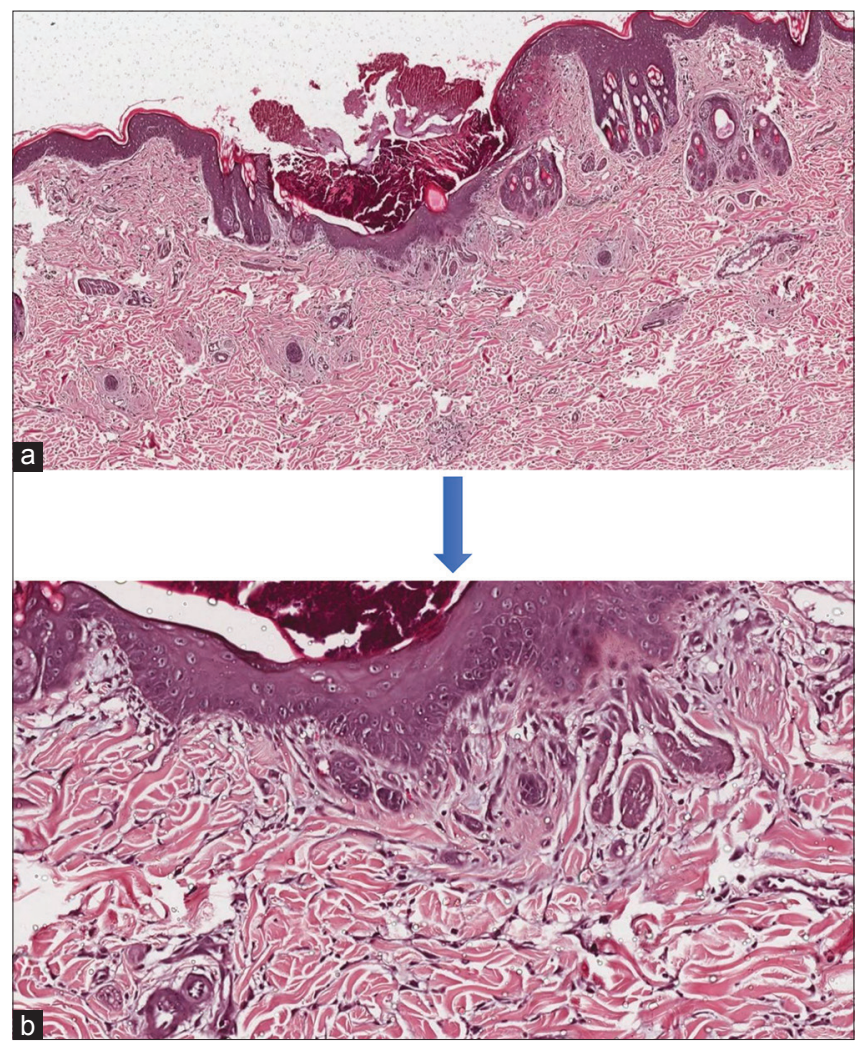

Figure 3: Histopathological photomicrograph of non-diabetic rabbits skin tissue stained with $H$ and $E$. (a) Skin wound section of non-diabetic rabbit treated with flaxseed oil $(\times 500 \mu \mathrm{m}),(\mathrm{b})$ Skin wound section of non-diabetic rabbit treated with flaxseed oil (100 $\mu \mathrm{m}$ magnification). ( $a$ and b) Photomicrograph showing the histological analysis of skin wound healing of non-diabetic animals at day 4 interval after $H$ and $E$ staining at 500 um (Low power) and $100 \mu \mathrm{m}$ (High power) magnification. All wounds were covered by scabs and there was clear demarcation between the unwounded area of epidermis and dermis from the wounded area consisting of epithelial tongues and provisional matrices containing inflammatory cells mean surface of control group was significantly the highest among NDM group followed by flaxseed then fucidin group ( $p=0.056$ ), while among DM group, the flaxseed was the highest followed by control then fucidin group ( $p=0.008)$ (Table 2).

d. New vessels formation parameter at day 4 shows that the mean new vessel of control group was the highest among NDM followed by flaxseed then fucidin. In regard to DM group, same distribution was observed. Nonetheless, the difference was not sizable to achieve statistical significance, $(p=0.328)$ and $(p=0.978)$, respectively (Table 2$)$.

\section{Summary of non-diabetic groups}

The non-treated group showed a highest rate of epithelization and surface closure despite sub-cutaneous edema followed by flaxseed which showed higher rate than fucidin treaded group at day 4 , likewise non-treated

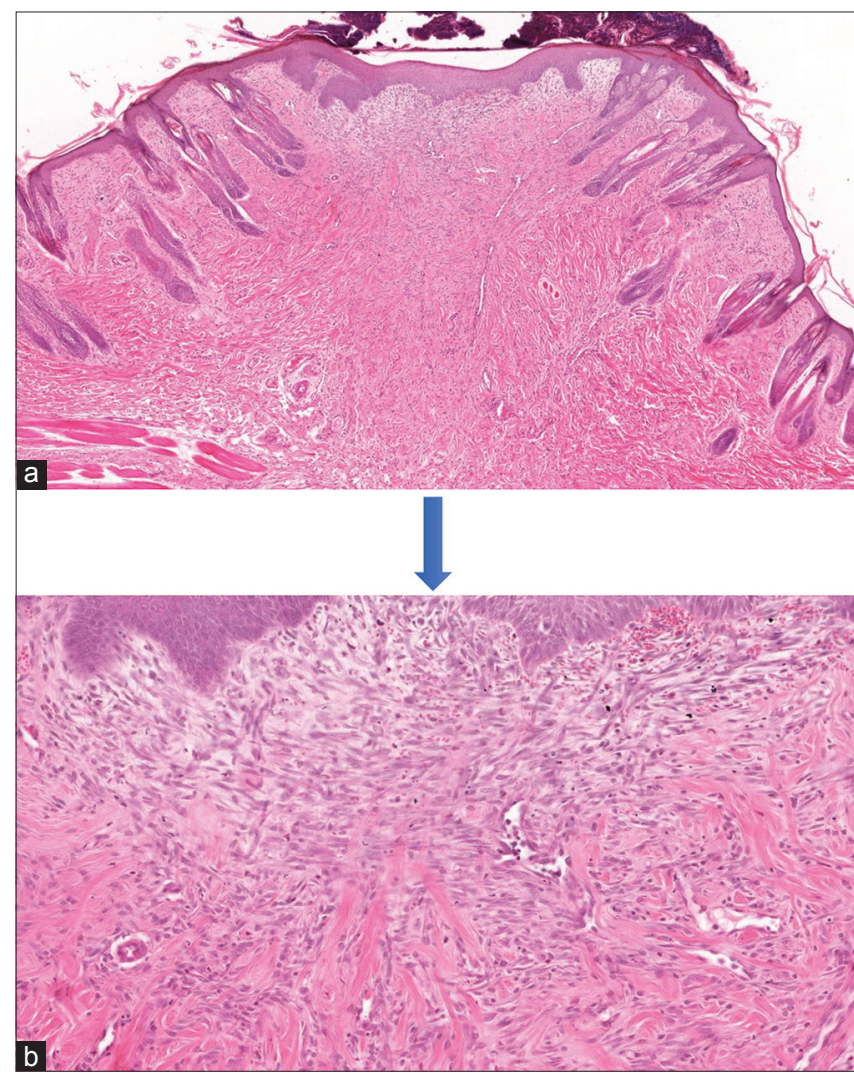

Figure 4: (a) Skin wound section of Non-diabetic rabbit treated with Flaxseed oil (500 $\mu \mathrm{m}$ magnification). (b) Skin wound section of Nondiabetic rabbit treated with Flaxseed oil. (100 $\mu \mathrm{m}$ magnification). (a and b) Photomicrograph showing the histological analysis of skin wound healing of non-diabetic animals at day 7 interval after $\mathrm{H}$ and $E$ staining at $500 \mu \mathrm{m}$ (Low power) and $100 \mu \mathrm{m}$ (High power) magnification. Flaxseed treated wounds still covered by scabs with a clear demarcation between the unwounded area of epidermis and dermis from the wounded area consisting of completely connected epithelial tongues and provisional matrices containing less inflammatory cells as compared to day 4 interval 
Table 2: A summary of semi-quantitative analysis of histological parameters mean values of diabetic and non-diabetic studied groups at day 4 post-wounding

\begin{tabular}{|c|c|c|c|c|c|c|c|c|c|}
\hline \multirow[t]{4}{*}{ Group } & & \multicolumn{8}{|c|}{ Day 4: Post wounding } \\
\hline & & \multicolumn{2}{|c|}{ Reepithelialization } & \multicolumn{2}{|c|}{ Inflammatory cells } & \multicolumn{2}{|c|}{ Surface closure rate } & \multicolumn{2}{|l|}{ New vessels } \\
\hline & & NDM & DM & NDM & DM & NDM & DM & NDM & $\mathrm{DM}$ \\
\hline & & Mean \pm SD & Mean \pm SD & Mean \pm SD & Mean \pm SD & Mean \pm SD & Mean \pm SD & Mean \pm SD & Mean \pm SD \\
\hline$T$ & IV & $1.33 \pm 0.516$ & $2.00 \pm 1.549$ & $3.17 \pm 0.983$ & $3.17 \pm 0.408$ & $1.83 \pm 0.983^{*}$ & $2.50 \pm 1.225^{*}$ & $3 \pm 0.516$ & $3.17 \pm 0.516$ \\
\hline III & $\mathrm{VI}$ & $2.00 \pm 1.265$ & $1.50 \pm 0.837$ & $3.00 \pm 0.000$ & $3.17 \pm 0.408$ & $2.83 \pm 0.983^{*}$ & $2.33 \pm 1.033^{*}$ & $3.67 \pm 0.516$ & $3.67 \pm 0.516$ \\
\hline II & $\mathrm{V}$ & $1.17 \pm 1.472$ & $0.67 \pm 0.516$ & $3.17 \pm 1.169$ & $3.67 \pm 0.516$ & $1.17 \pm 1.472^{*}$ & $0.67 \pm 0.516^{*}$ & $2.50 \pm 0.753$ & $3.00 \pm 0.816$ \\
\hline \multicolumn{2}{|c|}{$p$ value } & 0.273 & 0.080 & 0.637 & 0.119 & 0.056 & 0.008 & 0.328 & 0.978 \\
\hline
\end{tabular}

$N D M ; ~ I V=$ flaxseed $D M ; V=$ fucidin $D M ; V I=$ Non-treated DM. Values were expressed as mean $\pm S D(n=9)$. *Symbol means the statistical difference was significant $(p \leq 0.05)$.

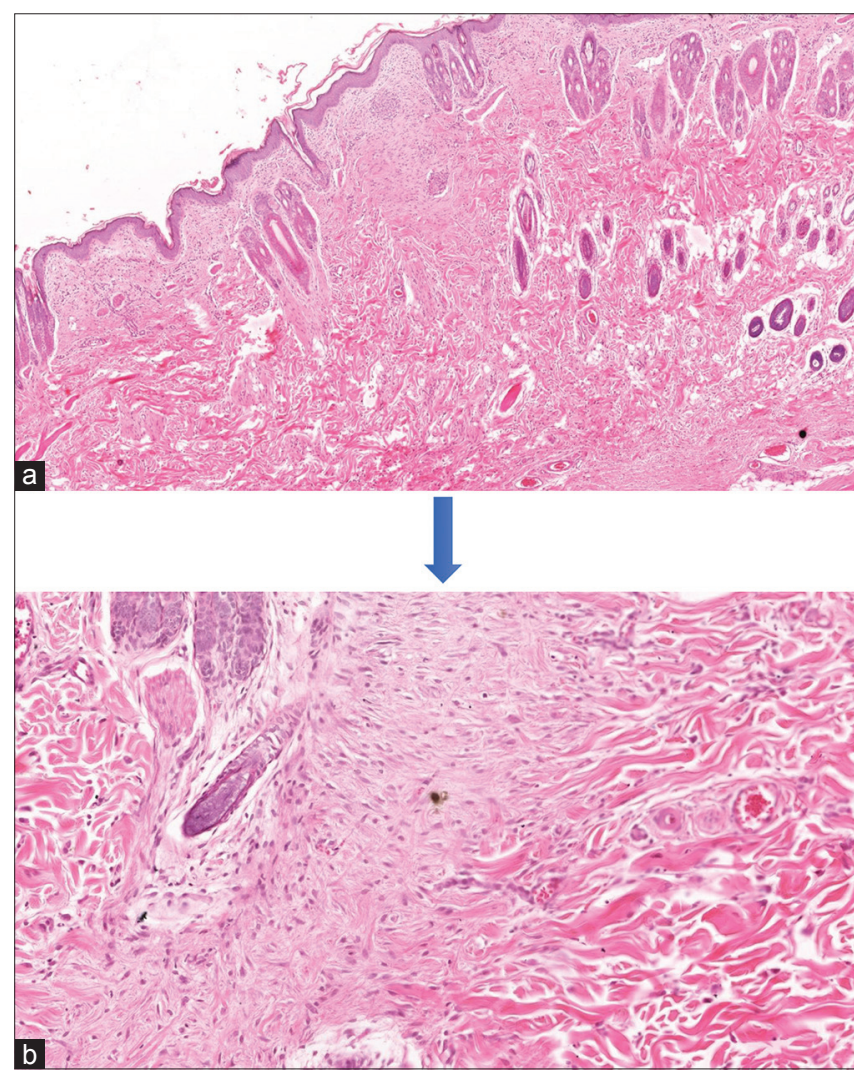

Figure 5: (a) Skin wound section of non-diabetic rabbit treated with Flaxseed oil. (500 $\mu \mathrm{m}$ magnification). (b) Skin wound section of nondiabetic rabbit treated with Flaxseed oil. (100 um magnification). (a and b) Photomicrograph showing the histological analysis of skin wound healing of non-diabetic animals at day 14 interval after $H$ and $E$ staining at $500 \mu \mathrm{m}$ (Low power) and $100 \mu \mathrm{m}$ (High power) magnification. The scabs had been detached on all wounds with an indistinct demarcation between the unwounded area of epidermis and dermis from the wounded area. The epidermis had been fully regenerated forming completely matured epithelial cells covering immature matrices with scant inflammatory cells as compared to day 7 interval

group showed a highest number of fibroblast cells proliferation for angiogenesis, followed by flaxseed and fucidin treated group. The highest rate of inflammatory cells infiltration PMNL was shown in fucidin group. While the flaxseed treated group showed a highest rate of granulation tissue deposition by the presence of more organized collagen tissue compared to non-treated and Fucidin group as visible at day 4 interval.

\section{Summary of diabetic groups}

Remarkably, the flaxseed treated group showed a highest rate of epithelization and surface closure with

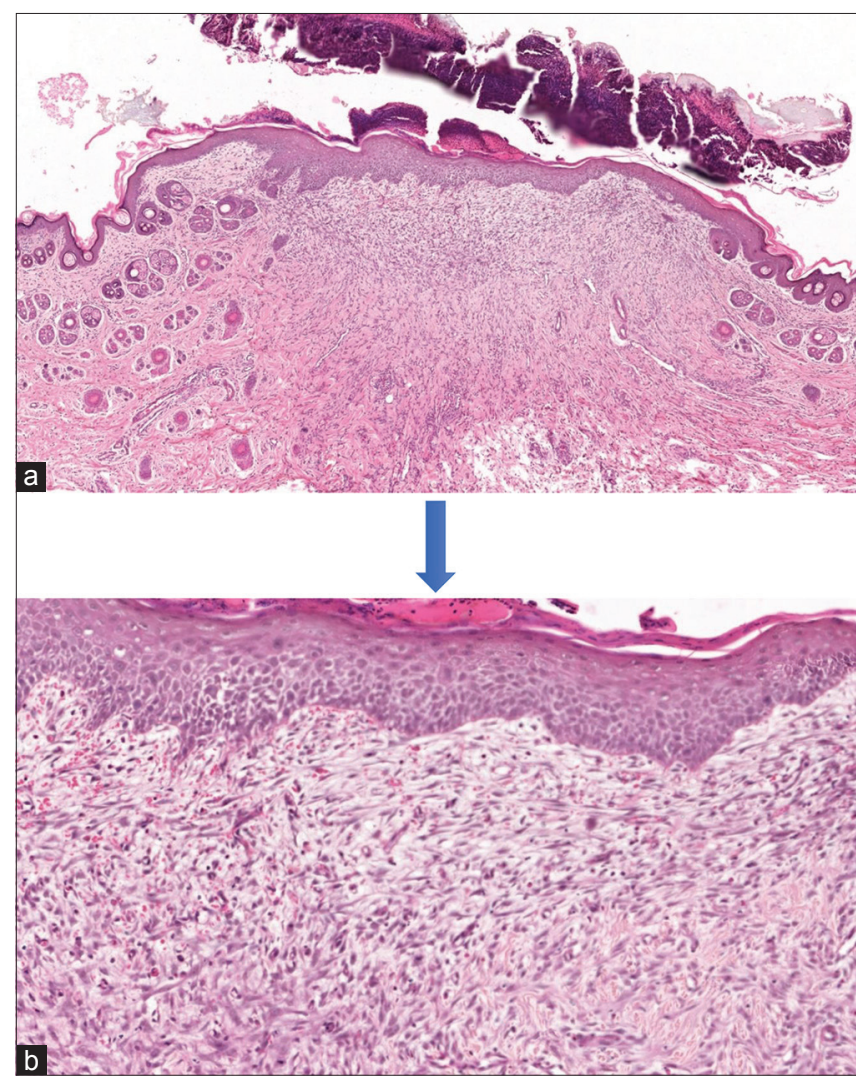

Figure 6: Histopathological photomicrograph of diabetic rabbits skin tissue stained with $H$ and $E$. (a) Skin wound section of diabetic rabbit treated with Flaxseed oil. (500 $\mu \mathrm{m}$ magnification). (b) Skin wound section of diabetic rabbit treated with flaxseed oil. (100 $\mu \mathrm{m}$ magnification). (a and b) Photomicrograph showing the histological analysis of skin wound healing of diabetic animals at day 4 interval after $\mathrm{H}$ and $\mathrm{E}$ staining at $500 \mu \mathrm{m}$ (Low power) and $100 \mu \mathrm{m}$ (High power) magnification. All wounds were covered by scabs and there was clear demarcation between the unwounded area of epidermis and dermis from the wounded area consisting of epithelial tongues and provisional matrices containing inflammatory cells

absence of sub-cutaneous edema as compared to fucidin and non-treated group, respectively. In regard to fibroblast cell proliferation, the non-treated group showed a highest rate of proliferation for angiogenesis (appear as cherry red), followed by flaxseed then fucidin treated group, the cell proliferation in flaxseed treated group of diabetic animals showed a higher rate as compared to non-diabetic animals. Although a highest rate of inflammatory cells infiltration PMNL was shown in fucidin treated group, flaxseed treated group showed a lower rate of granulation tissue deposition which almost equal to fucidin as compared to nontreated group. However, flaxseed in diabetic animals showed a lower rate of granulation tissue deposition 
as related to non-diabetic animals. Flaxseed treated group showed presence of more oriented, matured and organized collagen tissue compared to other groups in both diabetic and non-diabetic animals.

\section{Seven days after incisions preparation}

The histological findings shows complete re-epithelization of the surface, the incision side showed the presence of collagen fibbers (abundant), a moderate amount of inflammatory cell infiltration are evidence. The margins of the wound did not show hyperpigmentation of melanin due to absence of melanocyte in the basal cell layer of epithelium as shown in Figures 4-7.

a. Reepithelization parameter at day 7 of the NDM rabbit group did not show statistical significant despite the presence of mean difference $(p=0.160)$ i.e. the mean of reepithelialization of NDM rabbits was highest among flaxseed group then fucidin and lowest for control. In regards to DM rabbits, the difference reached border line statistical significance $(p=0.057)$ where the reepithelialization mean was highest among flaxseed group then fucidin and lowest for control by the $7^{\text {th }}$ day. Table 3 .

b. Inflammatory cell infiltration parameter at day 7 shown that the mean inflammatory cells of control group were the highest among NDM and DM group. Nonetheless, the difference was not sizable to achieve statistical significance, $(p=0.487)$ and $(p=0.489)$, respectively, (Table 3$)$.

c. Surface closure parameter at day 7 shown that the mean surface of flaxseed group was the highest among NDM and DM, followed by fucidin then control. Nonetheless, the difference was not sizable to achieve statistical significance, $(p=0.160)$ and $(p=0.057)$, respectively (Table 3 ).

d. New vessels formation parameter at day 7 shown that the mean new vessel of control group was the highest among NDM and DM, followed by fucidin then flaxseed. Nonetheless, the difference was not sizable to achieve statistical significance, $(p=0.125)$ and $(p=0.272)$ respectively, (Table 3$)$.

\section{Summary of non-diabetic groups}

The flaxseed treated group showed a highest rate of epithelization and surface closure without subcutaneous edema followed by fucidin which showed higher rate than non-treaded group at day 4, respectively, whereas non-treated group showed a highest number of fibroblast cells proliferation for angiogenesis followed by fucidin and flaxseed treated group. The lowest rate of inflammatory cells infiltration PMNL was shown in flaxseed treated group. However, the non-treated group showed a highest rate of granulation tissue deposition by the presence of more organized collagen tissue compared to flaxseed and fucidin treated group as visible at day 7 interval.

\section{Summary of diabetic groups}

Remarkably and same as in $4^{\text {th }}$ day interval, the flaxseed treated group showed the highest rate of epithelization and surface closure with absence of sub-cutaneous edema as compared to fucidin and nontreated group, respectively. In regard to fibroblast cell proliferation, the non-treated group showed a highest rate of proliferation for angiogenesis, followed by fucidin then flaxseed treated group which was higher in its rate than the non-diabetic animals, although flaxseed showed a highest rate of fibroblast cell proliferation, non-treated group showed the highest rate of new vascularization followed by fucidin and flaxseed treated group which showed a higher rate than non-diabetic animals. In the $7^{\text {th }}$ day interval, non-treated group showed a highest rate of inflammatory cells infiltration PMNL followed by flaxseed then fucidin treated group. Consequently, the non-treated group showed a highest rate of granulation tissue formation followed by flaxseed group which showed a higher rate than that of nondiabetic animals then the fucidin treated group.

\section{Fourteen day after incisions preparation}

The histological findings show relatively thin layer of epithelium covering the underling dermis, which was highly cellular fibrovascular connective tissue stroma with no evidence of skin appendage (hair follicle, sweat, and sebaceous gland) (Figure 5-8).

a. Reepithelization parameter at day 14 of the NDM rabbit did not show any mean difference $(p=1.000)$. In line with NDM group, the mean of DM rabbits was also equal between treatment

Table 3: A summary of semi-quantitative analysis of histological parameters mean values of diabetic and non-diabetic studied groups at day 7 post-wounding

\begin{tabular}{|c|c|c|c|c|c|c|c|c|c|}
\hline \multirow[t]{4}{*}{ Groups } & & \multicolumn{8}{|c|}{ Day 7 Post wounding } \\
\hline & & \multicolumn{2}{|c|}{ Reepithelialization } & \multicolumn{2}{|c|}{ Inflammatory cells } & \multicolumn{2}{|c|}{ Surface closure rate } & \multicolumn{2}{|l|}{ New vessels } \\
\hline & & NDM & DM & NDM & DM & NDM & DM & NDM & DM \\
\hline & & Mean \pm SD & Mean \pm SD & Mean \pm SD & Mean \pm SD & Mean \pm SD & Mean \pm SD & Mean \pm SD & Mean \pm SD \\
\hline$T$ & IV & $4.00 \pm 0.000$ & $4.00 \pm 0.000$ & $1.67 \pm 0.516$ & $2.67 \pm 0.816$ & $4.00 \pm 0.000$ & $4.00 \pm 0.000$ & $2.33 \pm 0.894$ & $2.67 \pm 0.816$ \\
\hline III & VI & $3.00 \pm 1.095$ & $2.67 \pm 1.033$ & $2.67 \pm 1.506$ & $2.83 \pm 1.472$ & $3.00 \pm 1.095$ & $2.67 \pm 1.033$ & $3.5 \pm 1.265$ & $3.5 \pm 1.329$ \\
\hline II & $\mathrm{V}$ & $3.33 \pm 1.033$ & $3.00 \pm 1.095$ & $2.00 \pm 0.894$ & $2.33 \pm 0.816$ & $3.33 \pm 1.033$ & $3.00 \pm 1.095$ & $2.5 \pm 0.516$ & $2.83 \pm 0.632$ \\
\hline$p$ value & & 0.160 & 0.057 & 0.487 & 0.489 & 0.160 & 0.057 & 0.125 & 0.272 \\
\hline
\end{tabular}


groups $(p=1.000)$ (Table 4$)$.

b. Inflammatory cell infiltration parameter at day 14 shown that the mean inflammatory cells of fucidin group were the highest among NDM group, followed by flaxseed then control group $(p=0.006)$, while flaxseed showed lowest mean value than fucidin and the negative control group in the DM group ( $p=0.009)$ (Table 4).

c. Surface closure parameter at day 14 of the NDM rabbit did not show any mean difference $(p=1.000)$. In line with NDM group, the mean of DM rabbits was also equal between treatment groups ( $p=1.000$ ) (Table 4$)$.

d. New vessels formation parameter at day 14

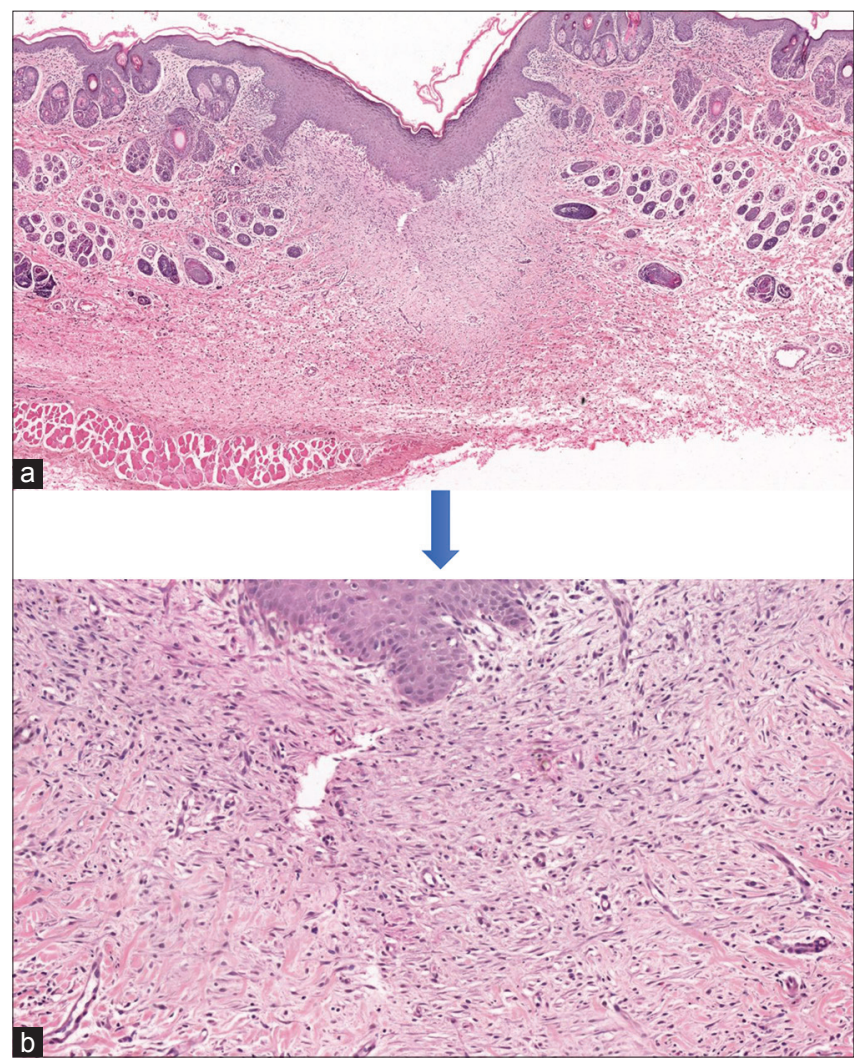

Figure 7: (a) Skin wound section of diabetic rabbit treated with Flaxseed oil. (500 $\mu \mathrm{m}$ magnification). (b) Skin wound section of diabetic rabbit treated with flaxseed oil. (100 um magnification). (a and b) Photomicrograph showing the histological analysis of skin wound healing of diabetic animals at day 7 interval after $H$ and $E$ staining at $500 \mu \mathrm{m}$ (Low power) and $100 \mu \mathrm{m}$ (High power) magnification. All wounds were covered by scabs and there was clear demarcation between the unwounded area of epidermis and dermis from the wounded area consisting of epithelial tongues and provisional matrices containing inflammatory cells shown that the mean new vessel of fucidin group was significantly the highest among NDM group followed by flaxseed then control group ( $p=0.002)$ while flaxseed showed higher mean than fucidin and the control group in the DM group $(p=0.002)$ (Table 4$)$.

\section{Summary of non-diabetic groups}

All wounds showed a highest rate of epithelization and surface closure since healing process getting advanced through this interval. Altered from the

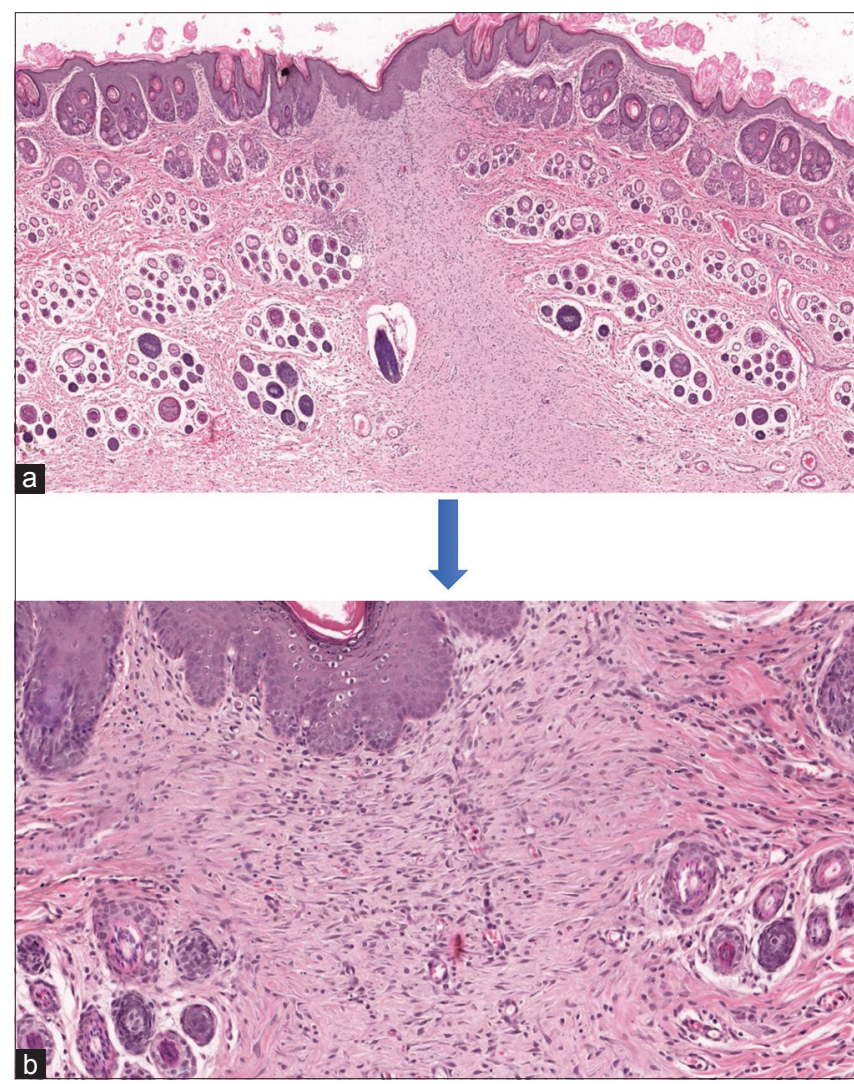

Figure 8: (a) Skin wound section of diabetic rabbit treated with flaxseed oil. (500 $\mu \mathrm{m}$ magnification). (b) Skin wound section of diabetic rabbit treated with flaxseed oil. (100 $\mu \mathrm{m}$ magnification). (a and b): Photomicrograph showing the histological analysis of skin wound healing of diabetic animals at day 14 interval after $H$ and $E$ staining at $500 \mu m$ (Low power) and $100 \mu m$ (High power) magnification. The scabs had been detached on all wounds with an indistinct demarcation between the unwounded area of epidermis and dermis from the wounded area. The epidermis had been fully regenerated forming completely matured epithelial cells covering immature matrices with scant inflammatory cells as compared to day 7 interval

Table 4: A summary of semi-quantitative analysis of histological parameters mean values of diabetic and non-diabetic studied groups at day 14 post-wounding

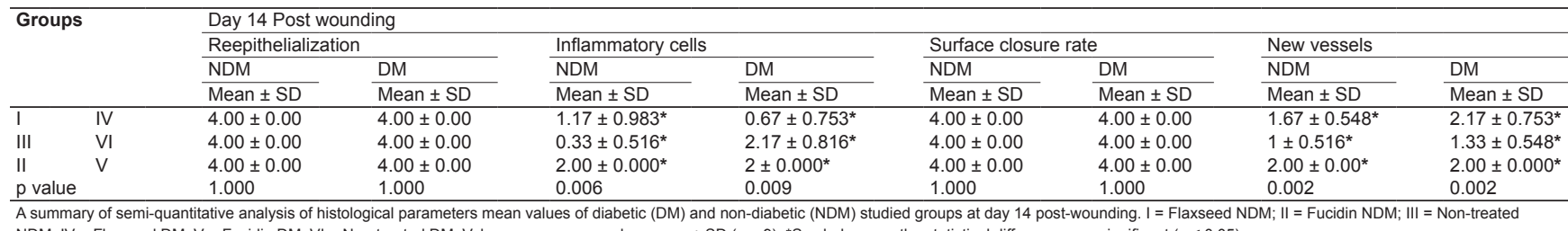

NDM; IV = Flaxseed DM; V = Fucidin DM; VI = Non-treated DM. Values were expressed as mean \pm SD $(n=9)$. * Symbol means the statistical difference was significant $(p \leq 0.05)$. 
previous intervals, fucidin treated group showed a highest number of fibroblast cells proliferation for angiogenesis, followed by flaxseed and non-treated group, respectively. Similarly, fucidin treated group showed a highest rate of inflammatory cells infiltration PMNL as shown in plates. Although mean values of granulation tissue deposition were low between all groups in 14 days interval, fucidin treated group showed a highest rate of granulation tissue deposition, followed by flaxseed then non-treated group as visible at day 14 interval.

\section{Summary of diabetic groups}

All wounds showed a highest rate of epithelization and surface closure since healing process getting advanced through this interval as visible in plate. Consistent to $7^{\text {th }}$ day intervals, flaxseed treated group showed a highest number of fibroblast cells proliferation for angiogenesis followed by fucidin then non-treated group, respectively. Similarly, flaxseed treated group showed a highest rate of inflammatory cells infiltration PMNL. Although mean value of granulation tissue deposition was low between all groups in 14 days interval, fucidin treated group showed a highest rate of granulation tissue deposition which was cut higher in many folds than the non-diabetic animals for same interval, followed by flaxseed then non-treated group as visible in plate.

\section{Discussion}

The healing of the injured mammalian skin is an extremely complicated and dynamic process involving a series of sequential and overlapping phases, including hemostasis, inflammation, proliferation, and remodeling. The process needs interactions between a variety of cell types, multiple cytokines, growth factors, and ECM [32]. The spontaneous healing of diabetic full-thickness skin wounds takes a protracted time and regularly end up in scar formation that becomes clinically apparent as hypertrophy, poor skin elasticity, and undesirable cosmetic appearance. Hence, dermal regeneration is important to boost the functional and cosmetic outcomes in the healing of full-thickness skin defects [32]. Crude flaxseed extract is presently used for wound healing and tissue regeneration. Their role in tissue regeneration is to produce the microarchitecture required for cellular infill and mechanical support to keep up tissue integrity throughout regeneration process [33].

Topical application of flaxseed extract on the full-thickness skin wounds in rabbits had provided better epithelization, new vascularization, and collagenization in comparison to control groups. The flaxseed oil promoted the biological activities that resulted in faster healing with significant decrease in the severity of inflammation of non-diabetic animals at $7^{\text {th }}$ day interval and $14^{\text {th }}$ day interval for STZ-induced diabetic animals, This activity might be related to the antigen masking activity of the flaxseed on lymphocyte proliferation [31]. In flaxseed exposed group both diabetic and nondiabetic animals, the epithelization and surface closure rate were more observable than that of control by days 4 and 7 , respectively. Whereas, the fucidin and nontreated group performed sub optimally findings in gross and histological features of healing process. This was in agreement with the finding of Molfino et al. [32].

The significant increase in closure rate of the surface area of the flaxseed exposed group at the $7^{\text {th }}$ day compared to the control was observed in both diabetic and non-diabetic animals for the same interval. This finding was not in agreement with Franco et al. 2012, who explained the therapeutic impact of petroleum jelly as control over flaxseed oil was due to occlusive and moisturizing action, through this mechanism, it prevents tissue from drying and prevents ischemia of deeper tissues, preventing the increase of the lesion [16]. Since the flaxseed extract occur in liquid form, it permits for faster absorption; however, increased exposure of the wound bed to the drying environment which leads consequently to the formation of scabs. Contrariwise, Demling and Desanti reported that the use of dressings has many functions, the primary being the protection of the wound to reduce the probabilities of infection and loss of water and electrolytes, with resultant dehydration of the wound bed [32]. Contrary to what was mentioned by Demling and Desanti, all created wounds in the current study treated with medication (fucidin) and exposed with study material (flaxseed) topically was without being dressed and covered showing (flaxseed) enhanced therapeutic potential with minimum formation of scabs subsequently.

Current study results were not the same as those of Otranto et al., 2010, who evaluated the healing activity in rats and found a significant difference in the amount of fibrin (slough) in animals that were orally supplemented with linseed oil when compared with control group, supplemented with water. The same authors conjointly recommended that the use of linseed and fish oil should be avoided whenever there is a tendency to fibrosis, as in hypertrophic scars and keloids. Thus, current study findings may lead us to conclude that flaxseed oil showed more therapeutic potential when applied topically rather than being used systematically.

Histological analysis performed in day 4 intervals disclosed that negative control group showed significant reepithelialization compared to flaxseed and fucidin treated groups, while the same positive finding was observed in flaxseed exposed group of both diabetic and non-diabetic animals at day 7 interval. One doable explanation for the absence of significant reepithelialization in flaxseed group can be attributed 
to the presence of high concentration of $\omega-3$ poly unsaturated fatty acids in relevance to non-treated group (negative control), whereas the high molecular weight of flaxseed particles may adversely interfere with surfaced keratinocytes migration and proliferation. In Addition, Altavilla also showed delayed wound healing as reflected in the decrease of reepithelialization of skin wounds in dogs fed a diet rich in $\omega-3$ poly unsaturated fatty acids. According to Altavilla, the delay in the healing process may be due to the presence of greater numbers of unsaturated bonds in $\omega-3$ poly unsaturated fatty acids, which is predisposed to lipid oxidation and consequently a delay in wound healing [37].

On the other hand, flaxseed oil significantly improved reepithelialization in diabetic animal at the early (day 4) and mid (day 7) phase healing interval subsequently. However, data on the effects of omega-3 fatty acids from flaxseed oil on skin wound healing in diabetic human studies are scarce (Zahra Soleimani, et al., 2017). McDaniel et al. 2008 demonstrated that omega-3 fatty acids supplementation in a healthy human population for 4 weeks resulted in increased production of pro-inflammatory cytokines, including IL-1B at wound sites and thus, depending on the clinical context have non-invasive, therapeutic potential to effect cutaneous wound healing. IL-1 assist in regulation of fibroblast proliferation and collagen synthesis (Efron and Moldawer, 2004); therefore, it can be posited that its initial upregulation at the wound sites, as a result of omega-3 fatty acids supplementation could be pathway to regulate collagen formation. Moreover, IL-1 expression increases keratinocytes growth, which is important for reepithelialization (Saunder et al., 1990).

Flaxseed effect on diabetic wound healing of the current study species was in agreement with a previous study that measured wound healing in dog models found a longer time for reepithelialization in surgical wounds after omega-3 fatty acids supplementation when compared with other dietary alterations (Mooney et al., 1998). Angiogenesis is essential to carry oxygen and nutrient to newly formed healing tissue [13]. In this study, new vascularization was highest in flaxseed exposed group of diabetic animals at the $14^{\text {th }}$ day interval compared to control groups of both diabetic and non-diabetic animals. This finding was in consistent with what been mentioned by McDaniel 2011 is that omega-3 fatty acids intake in microenvironment of acute human wounds improved wound healing, flaxseed was found to induce the production of IL-6, and has a stimulatory effect on angiogenesis process (McDaniel et al., 2011).

Rahimi et al. in 2013 mentioned in his study that Flaxseed and genistein inhibit angiogenesis in vitro by decreasing proliferation and migration of endothelial cells and reducing level of VEGF in tumors [46]. Thus, flaxseed may have an effect on angiogenesis through VEGF production both by direct cellular effects and indirectly by reducing the endogenous estrogen production. For instance, in Cardoso study it was reported that topical administration of omega-3 fatty acids to surgical wounds of mice significantly delayed wound closure in the first 10 days after surgery (Cardoso et al., 2004). Hence, the above-mentioned study suggests that the low angiogenesis rate seen in the rabbits when flaxseed oil administration may additionally be attributed to its result on angiogenesis phase of healing process.

Few studies have done to evaluate the effects of flaxseed on wound healing, considering that prolonged inflammation as in diabetic wounds can lead to delayed healing, administrating the anti-inflammatory agents is important for wound healing [43]. Excessive PMN activity in the microenvironment of wound successively ends up in biosynthesis of protease and neutrophilic elastase that finally leads to tissue destruction and persistent inflammation [44]. In this study, flaxseed exposed group non-diabetic animals showed diminished PMN and MNC distribution at the day 7 interval $(1.67 \pm 0.516)$, whereas diabetic animals showed diminished inflammation at the day 14 interval $(0.67 \pm 0.753)$. It is delineated that high flavonoid and phenolic acid contents of flaxseed oil offer a remarkable antioxidant and anti-inflammatory activity [43].

Zahra Soleimani study demonstrated that omega-3 fatty acids supplementation for 12 weeks subjects with diabetic foot ulcer was associated with significant decrease in serum inflammatory hs-CRP, and significant increase in plasma TAC (Total antioxidant capacity) and GSH (Plasma glutathione) levels, but did not influence plasma NO and MDA (Malondialdehyde) concentration. In addition, supplementation with omega-3 fatty acids in women with systemic lupus erythematosus for 12 weeks led to significant decrease of CRP levels, but did not alter serum concentration of IL-6 and IL-10 (Borges et al., 2016). However, supplementation with omega-3 fatty acids did not change serum CRP concentration among subjects with chronic inflammatory periodontitis after 6-weeks and 12-week treatment (Deore et al., 2014).

Flaxseed is great source of polyunsaturated fatty acids. According that flaxseed oil improves immune status index and have a tendency to decrease the delayed-type hypersensitivity reactivity. Thus, it is suggested that suppression of cell-mediated immunity by flaxseed oil appear to be helpful in treatment of autoimmune disease or inflammatory conditions [45]. As noticed, flaxseed oil suppressed PMN and MNC distribution particularly in diabetic groups at $7^{\text {th }}$ day interval. However, control groups exerted a better effect than flaxseed group in $4^{\text {th }}$ day intervals, the direct cellular and molecular mechanism for anti-inflammatory effect of poly unsaturated fatty acids on PMN regulation are still not fully understood [44]. Thus, the different in our findings with others might be explained by different study designs, and the source of PUFA, dosage and method of application of PUFA as well as duration of the study. 


\section{Conclusion}

Therapeutic analysis for medicinal plants is essential due to the growing interest in different therapies and the therapeutic application of natural products. Thus, synthetic drugs are much more expensive and may have side effects whereas plants are not only cheap but safe, so they will be used widely to treat wounds. Apparently, our results showed that flaxseed oil had curative impact on wound healing. Supported on that, flaxseed offered a regenerative medicine approach of full-thickness skin wound repair in STZ-induced diabetic rabbits. Therefore, its clinical application could also be potential may be possible to full-thickness skin wounds ensuing from varied pathologies, trauma and burn, we recommended further researches required to clarify potential interaction on wound healing pathways and flaxseed.

\section{Acknowledgments}

All the authors would like to thank International Islamic University Malaysia for this financial assistance. Additional abstract for new paper regarding DM and NDM.

\section{References}

1. Soleimani Z, Hashemdokht F, Bahmani F, Taghizadeh $M$, Memarzadeh MR, Asemi Z. Clinical and metabolic response to flaxseed oil omega-3 fatty acids supplementation in patients with diabetic foot ulcer: A randomized, double-blind, placebocontrolled trial. J Diabetes Complications. 2017;31(9):1394-400. https://doi.org/10.1016/j.jdiacomp.2017.06.010

PMid:28716357

2. Al-Ani IM, Abired AN, Mustafa BE, Wahab EN, Azzubaidi MS. Effect of flaxseed extract on the liver histological structure in streptozotocin induced diabetic rats. Int Med J Malaysia. 2017;16(1):91-8.

3. Järbrink $K$, Ni G, Sönnergren $H$, Schmidtchen $A$, Pang $C$, Bajpai R, et al. Prevalence and incidence of chronic wounds and related complications: A protocol for a systematic review. Syst Rev. 2016;5:152. https://doi.org/10.1186/s13643-016-0329-y

4. Peters EJ, Lipsky BA. Diagnosis and Management of Infection in the Diabetic Foot. Med Clin North Am. 2013;97(5):911-46. PMid:23992901

5. Larouche J, Sheoran S, Maruyama K, Martino MM. Immune regulation of skin wound healing: Mechanisms and novel therapeutic targets. Adv Wound Care (New Rochelle). 2018;7(7):209-31. https://doi.org/10.1089/wound.2017.0761 PMid:29984112

6. Gonzalez AC, Andrade ZD, Costa TF, Medrado AR Wound healing-a literature review. An Bras Dermatol. 2016:91(5):614-20 abd1806-4841.20164741

\section{PMid:27828635}

7. Landén NX, Li D, Ståhle M. Transition from inflammation to proliferation: A critical step during wound healing. Cell Mol Life Sci. 2016;73(20):3861-85. https://doi.org/10.1007/ s00018-016-2268-0

PMid:27180275

8. Burger B, Kühl CM, Candreva T, da S Cardoso R, Silva JR, Castelucci BG, et al. Oral administration of EPA-rich oil impairs collagen reorganization due to elevated production of IL-10 during skin wound healing in mice. Sci Rep. 2019;9(1):9119. https://doi.org/10.1038/s41598-019-45508-1

PMid:31235718

9. Jiang J, Li K, Wang F, Yang B, Fu Y, Zheng J. Effect of marinederived $n-3$ polyunsaturated fatty acids on major eicosanoids: A systematic review and meta-analysis from 18 randomized controlled trials. PLoS One. 2016;11(1):e0147351. https://doi. org/10.1371/journal.pone.0147351

PMid:26808318

10. Panahi Y, Dashti-Khavidaki S, Farnood F, Noshad H, Lotfi M, Gharekhani A. Therapeutic effects of omega-3 fatty acids on chronic kidney disease-associated pruritus: A literature review. Adv Pharm Bull. 2016;6(4):509-14. https://doi.org/10.15171/ apb.2016.064

PMid:28101457

11. Soleimani A, Taghizadeh M, Bahmani F, Badroj N, Asemi Z. Metabolic response to omega-3 fatty acid supplementation in patients with diabetic nephropathy: A randomized, double-blind, placebo-controlled trial. Clin Nutr. 2017;36(1):79-84. https://doi. org/10.1016/j.clnu.2015.11.003

PMid:26611718

12. Thakkar V, Korat V, Baldaniya L, Gohel M, Gandhi T, Patel N Development and characterization of novel hydrogel containing antimicrobial drug for treatment of burns. Int J Pharm Investig. 2016;6(3):158-68. https://doi.org/10.4103/2230-973x.187343 PMid:27606259

13. Estevão LR, Simões RS, Cassini-Vieira $P$, Canesso $M C$, da Silva Barcelos L, Rachid MA, et al. Schinus terebinthifolius raddi (Aroeira) leaves oil attenuates inflammatory responses in cutaneous wound healing in mice. Acta Cir Bras. 2017;32(9):72635. https://doi.org/10.1590/s0102-865020170090000005 PMid:29019590

14. Thomford NE, Senthebane DA, Rowe A, Munro D, Seele $P$ Maroyi A, et al. Natural products for drug discovery in the $21^{\text {st }}$ century: Innovations for novel drug discovery. Int J Mol Sci. 2018;19(6):1578. https://doi.org/10.3390/ijms19061578 PMid:29799486

15. El-Din Bekhit A, Shavandi A, Jodjaja T, Birch J. Flaxseed: Composition, detoxification, utilization, and opportunities. Biocatal Agric Biotechnol. 2018;13:129-52.

16. Beroual K, Agabou A, Abdeldjelil MC, Boutaghane $N$, Haouam S, Hamdi-Pacha Y. Evaluation of crude flaxseed (Linum usitatissimum L.) oil in burn wound healing in New Zealand rabbits. Afr J Tradit Complement Altern Med. 2017;14(3):280-6. https://doi.org/10.21010/ajtcam.v14i3.29 PMid:28480439

17. Layé S, Nadjar A, Joffre C, Bazinet RP. Anti-inflammatory effects of omega-3 fatty acids in the brain: Physiological mechanisms and relevance to pharmacology. Pharmacol Rev. 2018;70(1):1238. https://doi.org/10.1124/pr.117.014092 PMid:29217656

18. Ishak WM, Katas $\mathrm{H}$, Yuen NP, Abdullah MA, Zulfakar $\mathrm{MH}$. Topical application of omega-3, omega-6-, and omega-9rich oil emulsions for cutaneous wound healing in rats. Drug Deliv Transl Res. 2019;9(2):418-33. https://doi.org/10.1007/ s13346-018-0522-8 


\section{PMid:29667150}

19. Tu CF, Lee CH, Chen HN, Tsao LY, Chen JY, Hsiaoa CC. Effects of fish oil-containing lipid emulsions on retinopathy of prematurity in very low birth weight infants. Pediatr Neonatol. 2020;61(2):22430. https://doi.org/10.1016/j.pedneo.2019.11.010 PMid:31866497

20. Muhlhausler BS, Collins CT, Gould JF, Best KP, Leghi GE. Polyunsaturated Fatty Acids: Metabolism and Nutritional Requirements in Pregnancy and Infancy, Science Direct. United States: AOCS PRESS; 2018. p. 111-34. https://doi.org/10.1016/ b978-0-12-811230-4.00007-7

21. Dennis EA, Norris PC. Eicosanoid storm in infection and inflammation. Nat Rev Immunol. 2015;15(8):511-23. PMid:26139350

22. Padam MM, Khoshvaghti A. A comparative study on the effects of using hydroalcoholic extracts of linum usitatissimum and rosa damascena on liver function in adult male rats. Horizon Med Sci. 2019;26(1):54-67.

23. Chacińska M, Zabielski $P$, Książek M, Szałaj $P$, Jarząbek $K$, Kojta I, et al. The impact of omega- 3 fatty acids supplementation on insulin resistance and content of adipocytokines and biologically active lipids in adipose tissue of high-fat diet fed rats. Nutrients. 2019;11(4):835. https://doi.org/10.3390/nu11040835 PMid:31013835

24. Mustafa BE, Subramaniam PK, Mustafa NS, Kashmoola MA, Mokhtar KI, Qaralleh H. The anti-fungal effect of flax seed on oral candidiasis: Comparative in-vitro study. J Int Dent Med Res. 2018;580-586.

25. Knighton DR, Percoraro RE, Robson MC, Cooper DM, Margolis DJ, Rodeheaver G. Definitions and guidelines for assessment of wounds and evaluation of healing. Arch Dermatol. 1994;130(4):489-93. https://doi. org/10.1046/j.1524-475x.1994.20305.x

\section{PMid:8166487}

26. Maulidiania F, Khatib A, Perumal V, Suppaiah A, Ismail A, Hamid M, et al. Metabolic alteration in obese diabetes rats upon treatment with Centella asiatica extract. J Ethnopharmacol. 2016;180(2):60-9. https://doi.org/10.1016/j.jep.2016.01.001 PMid:26775274

27. Radwa I, Amal M, Mona A, Fotna E. Effects of Ginkgo biloba extract and troxerutin on the hippocampus of adult albino rats after induction of diabetes mellitus. J Adv Med Med Res. 2020;32(3):122-38. https://doi.org/10.9734/jammr/2020/ v32i330391

28. Mir MS, Darzi MM, Baba OK, Khan HM, Kamil SA, Sofi AH, et al. Streptozotocin induced acute clinical effects in rabbits (Oryctolagus cuniculus). Iran J Pathol. 2015;10(3):206-13. PMid:26351486

29. Al-Ahmad BE, Dally IM, Ahmed N, Abired AM, Emad MN. The effect of flax seed extract on the blood glucose level and liver bio markers in diabetic rats. World J Pharm Pharm Sci. 2019;8(8):780-98.

30. Jawad MM, Alam MK, Al-Kukash ST, Al-Azzawi LM, Husein A, Mahmood AS. Histological evaluation of incision healing response made by metallic scalpel on rabbits skin: Preliminary study. Int Med J. 2013;20(4):496-8.

31. Modupe IB, Oyepata SJ, Akpobome RV. Effect of Parkia biglobosa extract on open skin wound healing in dexamethasoneinduced hyperglycaemia and histological assessment in rats. Afr J Pharm Pharmacol. 2019;13(8):84-9. https://doi.org/10.5897/ ajpp2019.5043

32. Rousselle P, Montmasson M, Garnier C. Extracellular matrix contribution to skin wound re-epithelialization. Mat Biol. 2019;7576:12-26. https://doi.org/10.1016/j.matbio.2018.01.002 PMid:29330022
33. Draganescu D, Silion M, Ignat I, Sarghie C, Popa MI. Entrapment of flaxseed extract into xanthan-chitosan complex. Cell Chem Technol. 2013;47(3):231-8.

34. Bitto A, Altavilla D, Pizzino G, Irrera N, Pallio G, Colonna MR, Squadrito F. Inhibition of inflammasome activation improves the impaired pattern of healing in genetically diabetic mice. British Journal of Pharmacology (2014)1712300-230. DOI:10.1111/ bph.12557.

35. Chun HJ, Reis RL, Motta A, Khang G. Biomimicked Biomaterials: Advances in Tissue Engineering and Regenerative Medicine. Berlin, Germany: Springer; 2020. https://doi. org/10.1007/978-981-15-3262-7

36. Klek S. Omega-3 fatty acids in modern parenteral nutrition: A review of the current evidence. J Clin Med. 2016;5(3):34. PMid:26959070

37. Ishak WM, Katas $H$, Yuen NP, Abdullah MA, Zulfakar MH. Topical application of omega-3, omega-6-, and omega-9rich oil emulsions for cutaneous wound healing in rats. Drug Deliv TransI Res. 2019;9(2):418-33. https://doi.org/10.1007/ s13346-018-0522-8

PMid:29667150

38. Molfino A, Amabile MI, Monti M, Muscaritoli M. Omega-3 polyunsaturated fatty acids in critical illness: Antiinflammatory, proresolving, or both? Oxid Med Cell Longev. 2017;2017:5987082. https://doi.org/10.1155/2017/5987082 PMid:28694914

39. Clayton NA, Ward EC, Maitz PK. Orofacial contracture management outcomes following partial thickness facial burns. Burns. 2015;41(6):1291-7. https://doi.org/10.1016/j. burns.2015.02.015

PMid:26120089

40. Alahmad BE, Kashmoola MA, Subramaniam PK, Mokhtar KI, Mustafa NS, Jabbar OA, et al. The antibacterial effect of flaxseed extract on selective oral pathogens-comparative in vitro study. World J Pharm Pharm Sci. 2018;7(1):1-11. https:// doi.org/10.20473/ydk.v33i3.9826

41. de Sousa RG, de Nazaré Madureira Batista K. Laser therapy in wound healing associated with diabetes mellitus. An Bras Dermatol. 2016;91(4):489-93. https://doi.org/10.1590/ abd1806-4841.20163778 PMid:27579745

42. Eggleton P, Bishop A, Smerdon G. Safety and efficacy of hyperbaric oxygen therapy in chronic wound management: Current evidence. Chronic Wound Care Manag Res. 2015;2015:81-93. https://doi.org/10.2147/cwcmr.s60319

43. Alice DS, Luana GB, Monte-Alto-Costa A, Bruna RS. Supplementation with olive oil, but not fish oil, improves cutaneous wound healing in stressed mice. Wound Repair Regen. 2014;22(4):537-47. https://doi.org/10.1111/wrr.12191 PMid:25041622

44. Sridevi N, Chen L, Luisa AD, Jaques R, Alexander YM. Predictive approach identifies molecular targets and interventions to restore angiogenesis in wounds with delayed healing. Front Physiol. 2019;10:636. https://doi.org/10.3389/fphys.2019.00636 PMid:31191342

45. Marta S, González-Burgos E, Irene I, Gómez-Serranillos MP. Pharmacological update properties of Aloe vera and its major active constituents. Molecules. 2020;25(6):1324; https://doi. org/10.3390/molecules25061324 PMid:32183224

46. Berndt S, Issa ME, Carpentier G, Cuendet M. A Bivalent Role of Genistein in Sprouting Angiogenesis. Geneva, Switzerland: School of Pharmaceutical Sciences, University of Geneva; 2018. https://doi.org/10.1055/a-0587-5991

47. Ye D, LiZ, Wei C. Genistein inhibits the S-phase kinase-associated 
protein 2 expression in breast cancer cells. Exp Ther Med. 2017;15(1):1069-75. https://doi.org/10.3892/etm.2017.5489 PMid:29434697

48. Al-Snafi AE. Medical importance of Cupressus sempervirens-a review. Pharmacol Med Plants 2016;6(6):66-76.

49. McDaniel JC, Rausch J, Tan A. Impact of omega-3 fatty acid oral therapy on healing of chronic venous leg ulcers in older adults:
Study protocol for a randomized controlled single-center trial. Trials. 2020;93:820. https://doi.org/10.21203/rs.2.14638/v1

50. Demirdas S, van Spronsen FJ, Hollak CE, van der Lee JH, Bisschop PH, Vaz FM, et al. micronutrients, essential fatty acids and bone health in phenylketonuria. Ann Nutr Metab. 2017;70(2):111-21. https://doi.org/10.1159/000465529 PMid:28334709 